\section{Social validation of an objective measure of dominance in captive monkeys*}

\author{
STEVEN B. CHRISTOPHER \\ Eastern Washington State College, Cheney, Washington 99004
}

The validity of a primate dominance hierarchy was examined in terms of its relationship to social interactions. Twelve social behaviors associated with dominance and aggression were recorded during $61 \mathrm{~h}$ of observation of six pigtail macaques (Macaca nemestrina). Of the 1,462 interactions recorded, $94.7 \%$ were oriented in the water dominance hierarchy in the direction that would be predicted on the basis of their ascribed functions.

A fundamental concept of primate social behavior is the linear dominance hierarchy. This principle has had considerable appeal for investigators, in part due to the ease with which dominance of captive animals can be defined. Most measures involve relative priority of access to an incentive.

Boelkins (1967) recently developed a water dominance test which appears superior for some purposes to such traditional measures as the method of paired comparisons, food competition, or access to receptive females. The Boelkins technique offers a high degree of reliability, involves an objective measure which is simple to specify and record, and eliminates the possibility of an animal's gaining access to an incentive while two higher-ranking individuals are contesting for it. The principle of dominance, particularly as measured by the methods discussed above, has recently been attacked on the grounds of validity, that is, the relationship of the tested dominance rank to status in the more normal social interactions of primates (Gartlan, 1968). Since a long-term study of social dynamics and communication in primates was about to be initiated in this laboratory, it was important to examine the relationship between social rank derived from the water dominance test and a variety of other social behaviors. We wished also to consider ways in which dominance status might serve as a framework for analyzing social processes in groups of primates.

\section{METHOD}

The Ss were six adult pigtail macaques (Macaca nemestrina). Five were sexually mature females ranging

*The author thanks Miss Mary Khan, Mr. David Dau, and Mr. Thomas Haugen for collecting the data reported here. This research was supported by Grant RR00166 from the National Institutes of Health, and by the Primate Research Program of Eastem Washington State College. This is No. 2 in the publication series of the EWSC Primate Research Program. in weight from 5.0 to $6.7 \mathrm{~kg}$. The sixth $S$ was an adult male weighing $11 \mathrm{~kg}$. All Ss had been captured in Malaysia time of the study.

The animals were housed in a room measuring $3 \times 3.7 \times 3 \mathrm{~m}$. Commercial monkey chow was available in hoppers, and water was supplied through a pressure-activated drinking tube located $40 \mathrm{~cm}$ above the floor. An adjoining room equipped with a one-way observation window provided an unobstructed view of most of the animal quarters, including the drinking tube.

A catalog of social behaviors had been previously developed through observations of several groups of $M$. nemestrina in similar conditions. The patterns recorded were based primarily upon Kaufman and Rosenblum's (1966) behavioral taxonomy for this species, and upon van Hooff's (1967) classification of facial displays. The 12 behavior patterns reported here were selected because each had a cleariy identifiable recipient as well as an initiator, and all $h$ ad been described by various investigators as indicators of aggression and dominance, or fear, appeasement, and submission. The nine dominance-associated behaviors included a stare, an open-mouth stare, and seven kinds of aggressive encounters: chase, hit, bite, pull, push, grab, and displace. Three submissive behaviors were the lip smack, bared teeth with the animal silent, or bared teeth screaming. Thus, a total of 12 categories of behavior are considered in this report.

Twenty-four hours prior to the beginning of a water dominance test, the supply to the drinking tube was shut off. Immediately following this period, water was made available and observations began.

Data from $61 \mathrm{~h}$ of social observations were recorded and transcribed on tape recorders by two Os. From these transcriptions, frequency counts for each behavior in and were at least 7 years old at the terms of initiators and recipients were recorded in the cells of interaction matrices.

All water dominance data were recorded with an Esterline Angus 20-channel event recorder activated by pushbuttons on a remote-control panel. An $O$ pressed the button corresponding to a given $S$ as long as its lips or tongue were in physical contact with the drinking tube. Only one $S$ at a time was able to drink from the tube. Observations were terminated when all animals failed to drink for at least $10 \mathrm{~min}$. A second $O$ recorded social behavior during each test. The rank of each $S$ was later determined by the order in which it reached an elapsed drinking-time criterion of $30 \mathrm{sec}$. A total of five water dominance tests was conducted at intervals of 7 days.

\section{RESULTS}

The results of the water dominance tests indicated a stable linear hierarchy, with the male always reaching criterion first. Aggressive encounters were unusual during the tests. When a drinking animal was approached by a $S$ higher in rank, it moved aside. If the approaching animal was lower in rank, it was ignored. The approaching animal stood or sat nearby until the dominant monkey finished drinking. Queuing of three or more animals near the drinking tube was a common occurrence.

A total of 1,462 interactions involving the 12 patterns was recorded. These were analyzed in terms of their orientation in the water dominance hierarchy by noting the relative rank of the initiator and the recipient in each interaction. As Table 1 indicates, the behavior patterns fell into two classes, those with a high percentage of downward-directed interactions ("dominance associated") and those with a high percentage of upward-directed interactions ("submission associated"). Note that this division, based on an analysis of behaviors during the water dominance test, corresponds exactly with the functions ascribed to the patterns by other workers. That is, all patterns directed predominantly downward in the hierarchy are described as being characteristic of aggressive, threatening, or dominant animals: those directed predominantly upward have been said to be typical of appeasing, frightened, or submissive animals. In fact, $94.7 \%$ of all the behavior recorded was oriented in the direction that would be predicted on the basis of earlier descriptions of the functions of these patterns.

Another question of interest 
Table 1

Direction of Interactions in Hierarchy Based on Relative $R$ ank of Initiator and Recipient

\begin{tabular}{|c|c|c|c|}
\hline \multirow[b]{2}{*}{ Behavior } & \multicolumn{3}{|c|}{ Orientation in Hierarchy } \\
\hline & $\mathrm{N}$ & $\begin{array}{c}\text { Percent } \\
\text { Downward }\end{array}$ & $\begin{array}{l}\text { Percent } \\
\text { Upward }\end{array}$ \\
\hline \multicolumn{4}{|l|}{ Dominance Associated } \\
\hline Stare & 93 & 100 & $\mathbf{0}$ \\
\hline Gpen-mouth Stare & 259 & 87 & 13 \\
\hline Aggressive Encounters* & 1012 & 97 & 3 \\
\hline \multicolumn{4}{|l|}{ Submission Associated } \\
\hline Lip Smack & 46 & 0 & 100 \\
\hline Bared Teeth (Silent) & 14 & 29 & 71 \\
\hline Bared Teeth (Scream) & 38 & 0 & 100 \\
\hline
\end{tabular}

*Chase, hit, bite, pull, push, grab, displace concerned possible systematic relationships between the hierarchial distance in social rank between initiator and recipient and the relative probabilities that the patterns recorded would occur. Table 2 illustrates the influence of rank distance, regardless of direction, on the relative frequencies of the behaviors.

The proportions of open-mouth stares and aggressive encounters are directly correlated with the distance in rank between initiator and recipient. For example, $44 \%$ of the open-mouth stares were directed to animals ranking immediately above or below the initiator in the hierarchy; $30 \%$ were directed to animals two ranks higher or lower than the initiator, $8 \%$ were directed to animals three ranks higher

or lower, etc.

\section{DISCUSSION}

The issue of interest in this report centers on the question of whether or not the concept of a dominance hierarchy, as measured by the water access test, serves as a useful methodological tool in analyzing primate social behavior. The results of the current investigation suggest an affirmative answer, at least for captive groups of $M$. nemestrina. It was found that 12 separately recorded social behaviors which have been described as indicators of aggression, dominance, appeasement, or submission were strongly biased toward appropriate orientations within the objectively measured hierarchy. The social rank distance between animals as measured

Table 2

Effects of Distance* in Social Rank Between Initiator and Recipient on Relative Frequencies of Interactions

\begin{tabular}{|c|c|c|c|c|c|}
\hline \multirow[b]{2}{*}{ Behavior } & \multicolumn{5}{|c|}{ Social Rank Distance (Percent) } \\
\hline & 1 & 2 & 3 & 4 & 5 \\
\hline Stare & 25 & 26 & 15 & 26 & 8 \\
\hline Open-mouth Stare & 44 & 30 & 8 & 6 & 1 \\
\hline Aggressive Encounters & 58 & 25 & 11 & $\mathbf{5}$ & $\mathbf{1}$ \\
\hline Lip Smack & 15 & 33 & 17 & 20 & 15 \\
\hline Bared Teeth (Silent) & 36 & 43 & 0 & 21 & 0 \\
\hline Bared Teeth (Scream) & $\mathbf{9}$ & 50 & $\mathbf{3 5}$ & $\mathbf{0}$ & 6 \\
\hline
\end{tabular}

*Refers to position in hierarchy of recipient relative to initiator, regardless of direction, e.g., the figures in Column 1 indicate percentage of each behavior directed toward animals immediately adjacent in rank. by the water dominance test bore a systematic relationship to the probability of an interaction's occurring for several behavior patterns.

Several authors have recently pointed out the need for considering role analysis as a method in the investigation of primate social dynamics (Bernstein \& Sharpe, 1966; Crook, 1970; Gartlan, 1968; Rowell, 1966). Such analyses have been undertaken with the group of Ss reported here, as well as with similar groups of $M$, nemestrina. The latter work, although still in the preliminary stages, indicates that roles, or differences in the behavioral characteristics and functions of the individuals comprising a social group, also show variations which are associated with their positions in a dominance hierarchy.

One of Gartlan's (1968) central criticisms of dominance is based on the possibility that captivity exaggerates its influence on primate social behavior. This may well be true, although an equally likely possibility may be that the influence of dominance is just as great in free-ranging animals, although its manifestation is less obvious.

\section{REFERENCES}

BERNSTEIN, 1., \& SHARPE, L. Social roles in a rhesus monkey, group. Behaviour, $1968,26,81-104$.

BOELKINS, R. Determination of dominance hierarchies in monkeys. Psychonomic Science, 1967, 7, 317-318.

CROOK, J. Social organization and the environment: Aspects of contemporary social ethology. Animal Behaviour, 1970 . 18, 197-209.

GARTLAN, 3. Structure and function in primate society. Folia Primatologica, $1968,8,89-120$.

KAUFMAN, I. \& ROSENBLUM, L. A behavioral taxonomy for Macaco nemestrina and Macaca radiata: Based on longitudinal observation of family groups in the laboratory. Primates, 1966, 7 , 205-258.

ROWELL, J. Hierarchy in the organization of a captive baboon group. Animal Behaviour, 1966, 14, 430-458.

van HOOFF, J. The facial displays of the catarrhine monkeys and apes. In $D$. Morris (Ed.), Primate ethology. Chicago: Aldine, 1967 . 